\title{
The Opening Conference: A Case Study in Undergraduate Co-design and Inquiry-based Learning
}

\author{
*Zak Rakrouki, Mark Gatenby, Stefan Cantore, Tom Davidson, Thomas Rowledge \\ University of Southampton, United Kingdom.
}

Contact: zr2g13@soton.ac.uk

\section{ABSTRACT}

The separation between "research" and "teaching" in universities has been under increasing challenge from scholars who want to place inquiry-based learning at the centre of higher education. An important approach to challenging established paradigms and structures is to question, and thereby destabilise, role distinctions, relationships, language, and learning spaces. In this article we present a case study of a conference organized in collaboration between staff and students for first-year undergraduates. Reinventing the academic conference space is our aim in challenging assumptions about undergraduate education. As co-designers of the conference, we reflect on the activities and institutional context leading to the creation of the event, its design and implementation, and its impact on the undergraduate learning community.

KEYWORDS

Co-design, inquiry-based learning, conference, undergraduate, business schools

\section{INTRODUCTION}

In this article we want to explore an "inquiry-based learning" (IBL) approach, incorporating practices often considered the exclusive domain of research into a setting typically described as education or teaching. The case study example we provide is an "Opening Conference" for first-year undergraduate students co-designed by staff and students within a research-intensive UK university. A central motivation for this initiative was to explore the possibility of forming an IBL community with first-year undergraduates and working with staff and students in partnership to challenge the "conspiracy for safety" (Barnett, 1999, p. 164), which, arguably, has become the norm in HE learning design and 
delivery. The conference space we describe emerged through a co-design process and became an answer to many of the challenges the group faced in introducing undergraduates to new pedagogies, roles, and relationships. The shared aims for the conference were to: (a) create a space for building a collaborative learning environment and community; (b) introduce co-design principles to the community and invite participation in the co-design process; and (c) showcase co-design-in-action through the implementation of the conference, where students and staff share key roles in hosting the event.

We follow the ethos of staff-student partnership by offering a reflective account of a co-design process and by allowing the power dynamics of multiple actors working together to shape the narrative. Although we offer a coherent "single" narrative to structure the central thesis of the case study, we have enriched this narrative with individual verbatim statements from various members of the co-authorship team (as recorded in conversations between the authors in the process of preparing the text). We believe this approach offers a glimpse into the complex interdependent process of working in partnership, and importantly retains the distinct voices of both staff and students while resisting the temptation to conflate the two. The article is structured as follows: first we lay out our perspective on IBL and offer the academic conference as an important design space for alternative pedagogies; next we introduce the institutional context for the case study and describe the co-design process; and then we summarise the conference format and reflect on its impact from different perspectives.

\section{INQUIRY-BASED LEARNING}

IBL can be described as an "alternative" paradigm to what might be deemed the traditional approach of lecture-based modes of teaching. Levy, Little, McKinney, Nibbs, and Wood (2010) offer a simple definition for this as a "cluster of student-centred approaches to learning and teaching which are driven by inquiry or research" (p. 6). Research and learning are not fixed or exclusive objects as both are processes of inquiry in pursuit of meaning, understanding, and knowledge (Clarke, 1995). This way of thinking opens up new possibilities for HE, creating notions such as "pedagogy of joint discovery" (Barnett, 2007), or staff-student communities of "co-learners" (Le Heron, Baker, \& McEwen, 2011). Healey (2005) describes IBL as a "new pedagogy for the twenty-first century" (p. 197), and Healey and Jenkins (2009) suggest:

the task now is to reinvent or reinvigorate the curriculum to ensure that all undergraduate students in all higher education institutions should experience learning through and about research and inquiry. (p. 6)

The co-design group was formed in 2014/15 and met during the academic semester with a range of staff and students. A key focus for the group was to engage all undergraduate students from the start of their university learning journey in a way that went beyond institutionalised induction processes. As part of the EEF project plan, one third of the budget was allocated to travel and attending events, largely with the aim of disseminating our work as "research" but also as a way to learn and share with staff-student groups from other universities around the world. The group explored conferences and international workshops publicised by HE associations in the areas of learning technology, education development and innovation, student engagement, and interdisciplinary education. During the 2015/16 academic year the EEF budget funded co-attendance at eight conferences from April to October 2016, most of which were as presenters of papers or 
hosts of workshops (e.g., Cantore \& Gatenby, 2016; Gatenby, Cantore, Harris, Morgan, \& Davidson, 2016; Rowledge, Davidson, Harris, Fair, \& Gatenby, 2016).

In this article we follow a similar line of argument to Lueddeke (2003), Griffiths (2004), and subsequent scholars in characterising IBL as an "alternative," as a reaction against what became mainstream approaches to HE pedagogy during the 20th century. We also see IBL as more than a challenge to institutionalised teaching practices - it presupposes a theory of learning. The space in which "teaching" ends and "learning" starts becomes a central debate within IBL. It is an important theoretical question whether, as Justice et al. (2007) argue, IBL is both a process of seeking knowledge (i.e., learning) and a method of teaching, or if it is a more complex phenomenon that combines both. As Brew (1999) argues, IBL challenges assumptions and expectations about learning, including:

shifts in power relationships, the inclusion of different kinds of knowledge, learning perhaps becoming a collaborative process of engagement in a joint enterprise. They might involve the distinctions between teacher and student becoming less clear. ( $p$. 296)

Within an IBL paradigm, Spronken-Smith and Walker (2010) ask whether undergraduate students should start their first year in a "structured" mode of inquiry-closer to tutor-led lectures and seminars - and then move gradually towards an "open" inquiry approach, or whether they should start in an open discovery mode. Healey and Jenkins (2009) do not see the need to draw clear distinctions or set out a fixed path. Instead, they suggest students can participate in different approaches to research and inquiry from the first year onwards with a general trajectory to more open modes.

\section{The conference space}

The academic conference emerges as an important design space within an IBL perspective as it offering participants the opportunity to meet as inquirers, to ask questions together, and to exchange ideas. Conferences are fundamental to the research process in all academic disciplines and they are also critical for professional practice development. Conferences become spaces for the formation and reproduction of learning communities, and they can facilitate the social process of learning fundamental to many theories of knowledge (Bandura, 1971). Conferences can be open to all learners, from the uninitiated novice to the experienced scholar. In this sense, conferences can be seen as a natural domain for strengthening the teaching-research nexus.

There have been various attempts over the past decade in particular to incorporate the conference spaces into undergraduate learning. In the UK, the British Conference of Undergraduate Research (BCUR) has been hosting an annual student-led research conference since 2011. A related UK organization, Researching, Advancing and Inspiring Student Engagement (RAISE), has also hosted an annual conference since 2011. These conferences have offered a forum to showcase the outcomes of IBL at the level of individual $\mathrm{HE}$ institutions. Additionally, a small literature has grown around student-led or co-led conferences embedded within course design. These conferences take place at the end of a semester or academic year and may form part of the summative assessment for a particular course (e.g., Davis and White, 2005; Garde-Hansen and Calvert, 2007).

In this article we explore a new use for the conference space as a way to initiate an $\mathrm{IBL}$ community (in contrast to its more typical use of showcasing and providing closure to student research outcomes). We agree with Schwartz's (1995) statement that "the question is not how individuals become members in a larger cognitive community . . . the question is 
how a cognitive community could emerge in the first place" (350). We have not found any examples of this approach to the conference space in prior literature on undergraduate research or IBL.

\section{Institutional context}

The case study takes place within Southampton Business School, which is part of the University of Southampton in the UK. Sitting within the Faculty for Business, Law and Art, the School is one of the largest departments of the University with 2,000 students (900 of which are undergraduates) and 120 full time staff. In recent years, Southampton Business School has set out to transform the process of undergraduate curriculum design and delivery through the creation of a new set of modules as part of a common first year. The aim was to fundamentally restructure the governance of undergraduate education by working with students as partners in the creation and ownership of the learning environment, and by harnessing the openness and scalability of digital resources to enhance student engagement. An integral part of this process was the formation of a staff-student co-design group, which was funded by the University's Education Enhancement Fund (EEF), an institution-wide initiative using alumni donations to support education innovation. The Students as Creators EEF project was designed to act as a catalyst for education innovations in the faculty. Senior management advocacy was an essential part of the funding for the group. The initial project ran from October 2014 to July 2016, and it involved a wide range of staff and students from the School along with student learning champions, named Digichamps, from the wider university.

\section{Co-attending conferences}

On joining the co-design group, none of the undergraduate student members had attended an academic conference before. The idea for the Opening Conference came from discussions in the co-design group meeting immediately after returning from the International Summer Institute on Students as Partners, hosted by McMaster University in Hamilton, Canada (May 2016). Three members of the co-design group attended the Summer Institute, and the idea for the Opening Conference emerged, in part, from the returning students explaining to other group members what a conference actually entailed and the potential of conferences to transform staff-student relationships.

A conference became the obvious way to combine many of the other initiatives the group had been discussing around undergraduate pre-arrival, cohort induction, and the introduction of the ethos of staff-student partnership. As one members of the group suggested, reflecting back on the experience of key co-design meetings:

The enthusiasm of co-design colleagues returning from an academic conference sparked the idea of co-creating a conference for newly arrived first year undergraduates at the very start of their programme. Reflecting on that conference experience, it was the networking and exchange of ideas that really energised people. What if we could adopt a similar conference format to spark energy and productive learning relationships for newcomers? (Staff member of the co-design group)

Another member explains:

We realised a conference is a place where students could socialise and network with one another, engage with the lecturers and academics, and begin to define for themselves what it means to be in an inclusive learning community. All of these 
outcomes were predicted by students, after our experiences attending conferences. (Undergraduate co-design group member)

\section{Co-design and Implementation}

Once the group had decided to design the conference, and had secured resources within the School to support its implementation, the process of design could begin. From the May 2016's co-design meeting we had four months to prepare for its planned delivery in the first week of autumn semester (October 2016). A member from the group has provided the following account the co-design process during this period:

When work on creating the scope, content, and format of the conference began, we realised that, not only were we introducing the first years to a new framework for true collaboration, in the form of co-design, but that we had to place this in the context of their "school to higher education" transition. We often found ourselves asking what the incoming students would be expecting from the conference. We realised that this would be the first time they would meet many of their fellow colleagues, and that it would be their first glimpse of university academic content, debate and discussion. We also accepted that combining this via the medium of co-design would be daunting for most. Indeed, it became apparent a large amount of "managing expectations" would have to occur, not only within the context of the Opening Conference, but within the entire context of introducing this new framework of education. Yet, we felt that a short, sharp shock that combined the ethos of partnership with an introduction to undergraduate research within the context of the Opening Conference would be the best way for incoming colleagues to notice a change so substantial, that they would be obliged to begin to realise the difference in how they would learn at university.

With the purpose of the conference set we came together to create the content of the conference. As ever when speaking about partnership in the context of higher education, we had difficulty deciding on the language we would be using. Did we use "co-design," "co-creation," or "partnership," or did we use "colleague" or "staff/student"? Our main concern was that we didn't want the terminology of the conference to sound so foreign as to put them off.

We intended to treat this Opening Conference like any other conference an academic would attend, and we did. Formal invitations were sent out where colleagues had to register, a "Business-Smart" dress code was set and name tags were prepared. We put together a Southampton Business School branded "conference pack" which contained some further reading material, an attendee list, and a welcome letter from the co-design group. The latter inclusion, we felt, was very important. The letter was the formal, personalised recognition that they were now part of a distinct, new, and professional community at university. To stimulate conversation, we used circular tables. (Undergraduate co-design group member)

\section{The Conference Format}

It was decided that a half-day conference was sufficient for what we aimed to achieve. The event was planned for the Monday of Week 1 of the semester-it would be the very first learning experience the first year students would have in their degree programme. Registration on the day commenced at 9:30 a.m., where colleagues picked up their 
conference pack and name badge. At 10:00 a.m. the conference began and was opened by one of the second-year undergraduate members of the co-design group. The remainder of the conference format is summarised in Table 1. The schedule included a balance between staff and student contributions, with many of the sessions jointly hosted and led by members of the group. The event was attended by 190 first-year students ( $90 \%$ of those who were invited), by eight second-year members of the co-design group, and nine members of staff from the School's undergraduate programmes.

Table 1.

\begin{tabular}{|c|c|}
\hline Time & Activity \\
\hline $\begin{array}{l}10.00- \\
10.20\end{array}$ & $\begin{array}{l}\text { Welcome, introduction to the day, meeting the team and table } \\
\text { conversations - introduction by students and staff }\end{array}$ \\
\hline $\begin{array}{l}10.20- \\
11.20\end{array}$ & $\begin{array}{l}\text { Subject-specific discussion - led by staff } \\
\text { Interactive work on current business new stories. }\end{array}$ \\
\hline $\begin{array}{l}11.20- \\
12.10\end{array}$ & $\begin{array}{l}\text { What exactly is the Business World? - led by staff and students } \\
\text { Conversations (with tweeting - students encouraged to sign up to co- } \\
\text { design twitter feed and student-led blog) }\end{array}$ \\
\hline $\begin{array}{l}12.10- \\
12.30\end{array}$ & Lunch Break \\
\hline $\begin{array}{l}12.30- \\
13.15\end{array}$ & $\begin{array}{l}\text { Co-creation and Co-design - led by students } \\
\text { Getting to grips with programme co-design and involvement. }\end{array}$ \\
\hline $\begin{array}{l}13.15- \\
14.15\end{array}$ & $\begin{array}{l}\text { Establishing Enterprises - led by staff and students } \\
\text { Launching the "Boeing Fund" and working out some next steps. } \\
\text { Our Programme Charter } \\
\text { How are we going to make it work for all of us? }\end{array}$ \\
\hline $\begin{array}{l}14.15- \\
14.20\end{array}$ & Next Steps - led by staff \\
\hline $\begin{array}{l}14.20- \\
14.30\end{array}$ & Announcements and Close \\
\hline
\end{tabular}

\section{Impact of the conference}

The attendance, level of engagement, and feedback from the conference has been very strong. We were able to capture the ethos of the co-design approach and allow students to experience a conference which was integral to their course design. As an undergraduate member of the group reflects when looking back at the day:

The reaction from our new colleagues to the fact that second years were an integral part in creating, preparing, and running the conference was one of surprise, disbelief, and sometimes scepticism. While they did not understand the full implications of what exactly the co-design group did, they realised implicitly that there had been a paradigm shift in their new educational environment. This was 
merely the beginning of their journey into the world of partnership and undergraduate research.

A staff member of the co-design group gives the following observation of the impact of the event:

My observation is that it was not only the leadership role of students that impacted newcomers but perhaps even more significantly the stepping back of the teachers into a complementary position signalled that power and control in this community was open to being shared. I don't think the impact of this can be under estimated since the conference encouraged the newcomer to perceive that learning at university was going to be different from what most had previously experienced, emphasising in particular the essential role they needed to play individually and collectively to co-create transformational learning experiences.

A feedback questionnaire was circulated to all attendees and was completed the end of the day in the closing session. The staff member who led this closing session reflects on the day:

Feedback gathered through a questionnaire indicated that students overwhelmingly (90\%) appreciated the opportunity to get to know one another as the primary success of the event. The learning about the content of the programme was well down in fourth place (54\%) behind understanding co-design group activities and forming enterprise cooperatives. This speaks of the students' need to create trust and a sense of safety as a precursor to learning in a community context. The willingness of students to engage subsequently with one another in classes and café conversation events is some evidence of how the conference helped create the conditions for community learning.

\section{DISCUSSIONS AND CONCLUSIONS}

We have explored the conference space as an effective way to combine co-design with IBL in undergraduate education. The Opening Conference emerged as an opportunity to: (a) create a space for building a collaborative learning environment and community; (b) introduce co-design principles to the community and invite participation in the co-design process; and (c) showcase co-design-in-action through the delivery of the conference. The format of the conference was an effective way to showcase the potential of co-design in shaping IBL. There was a balance of contributions between staff and students, with many of the sessions being jointly led. The conference activities were designed to encourage students to meet each other as colleagues and co-inquirers, to create new profiles as researchers, and to begin their own inquiry process into their chosen subject. As Healey and Jenkins (2009) recommend, this event offered a combination of "structured" and "open" modes of inquiry.

As co-design members, our experiences of running the conference were mostly quite positive from a learning perspective. The attendance, level of engagement, and detailed feedback suggest the event had an impact on the first-year students, particularly as a social opportunity to meet new colleagues framed as co-inquirers. The incoming students were aware that this approach offered an "alternative" to mainstream methods of teaching in higher education (Brew, 1999; Garde-Hansen and Calvert, 2007; Lueddeke, 2003). This event presented an opportunity to shape expectations in what was a novel learning environment for most in attendance, and it allowed the co-design group to introduce a range of themes 
that would have been difficult to convey in a lecture or seminar environment. The conference format was therefore well designed to challenge the "conspiracy for safety" in education that sees students fitting into a passive role (Barnett, 1999). The conference's ability to showcase co-design through the role modelling of second-year students and through a new language for learning perhaps had the most impact on the cohort.

The weaknesses of the approach were largely found in the difficulty of engaging the minority of students who found the experience difficult to understand and appreciate. This suggests that some students may have already "fixed" their role expectations before entering university and that they need more dedicated support (or challenge) in exploring their role in the process of inquiry. Building on Spronken-Smith and Walker's (2010) work, we need to consider to what extent a conference format can offer different levels of inquiry structure to meet the development and expectations of a wide-range of individual learners. This is an area for further investigation and experimentation in both the IBL and student-aspartners literature.

Our experience of working within the conference space alongside undergraduate students has suggested this approach has significant potential to create IBL communities. A future aim of the group is to hold an end-of-year Closing Conference organized through a process of co-design with the first-year undergraduate students themselves. This will give symmetry to the Opening Conference and will offer an opportunity to take stock of the undergraduates progressed in their first year of study. It is through this longitudinal approach to building a community and culture of co-inquiry that we think offers the most potential for strengthening the teaching-research nexus.

\section{NOTE ON CONTRIBUTORS}

Zak Rakrouki is an undergraduate student in Business Management at the University of Southampton.

Mark Gatenby is an Associate Professor in Organizations, Director of programmes for BSC Business Management at the University of Southampton.

Stefan Cantore Principal Teaching Fellow in Organizational Behaviour and HRM, Director of Enterprise at the University of Southampton.

Tom Davidson is an undergraduate student in Web Science at the University of Southampton.

Thomas Rowledge is an undergraduate student in Web Science at the University of Southampton.

\section{REFERENCES}

Bandura, A. (1971). Social learning theory. New York: General Learning Press.

Barnett, R. (1999). Realizing the university. London: McGraw-Hill Education (UK).

Barnett, R. (2007). Will to learn: Being a student in an age of uncertainty. London: McGrawHill Education (UK). 
Brew, A. (1999). Research and teaching: Changing relationships in a changing context. Studies in Higher Education, 24(3), 291-301.

Cantore, S., \& Gatenby, M. (2016). "Do you mean I can study what I am really interested in?" Practicing self-managed learning in UK business schools. British Academy of Management annual conference, Newcastle Upon Tyne, 6 September, British Academy of Management.

Clark, B. (1995). Places of inquiry: Research and advanced education in modern universities. Los Angeles: University of California Press.

Davis, H., \& White, S. (2005, June). A research-led curriculum in multimedia: Learning about convergence. In ACM SIGCSE Bulletin, 37(3), 29-33.

Garde-Hansen, J., \& Calvert, B. (2007). Developing a research culture in the undergraduate curriculum. Active Learning in Higher Education, 8(2), 105-116.

Gatenby, M., Cantore, S, Harris, L., Morgan, A., \& Davidson, T. (2016). Business education and curriculum co-creation in the digital age. Chartered Association of Business School learning, teaching and student experience conference, Birmingham, UK, 26 April, Chartered Association of Business Schools.

Griffiths, R. (2004). Knowledge production and the research-teaching nexus: The case of the built environment disciplines. Studies in Higher education, 29(6), 709-726.

Healey, M. (2005). Linking research and teaching exploring disciplinary spaces and the role of inquiry-based learning. In R. Barnett (Ed.), Reshaping the university: New relationships between research, scholarship and teaching (pp. 67-78). London: McGraw Hill/Open University Press.

Healey, M., \& Jenkins, A. (2009). Developing undergraduate research and inquiry. London: HEA.

Justice, C., Rice, J., Warry, W., Inglis, S., Miller, S., \& Sammon, S. (2007). Inquiry in higher education: Reflections and directions on course design and teaching methods. Innovative Higher Education, 31(4), 201-214.

Le Heron, R., Baker, R.m \& McEwen, L. (2011). Co-learning: Re-linking research and teaching in geography. Journal of Geography in Higher Education, 30(1), 77-87.

Levy, P., Little, S., McKinney, P., Nibbs, A., \& Wood, J. (2010). The Sheffield companion to inquiry-based learning. Centre for Inquiry-based Learning in the Arts and Social Sciences (CILASS), Sheffield: University of Sheffield.

Lueddeke, G. R. (2003). Professionalising Teaching Practice in Higher Education: a study of disciplinary variation and 'teaching-scholarship', Studies in Higher Education, 28(2), 213-228.

Rowledge, T., Davidson, T., Harris, L., Fair, N., \& Gatenby, M. (2016). Creating and sharing content through open virtual platforms: The student perspective. EDULEARN16 Proceedings, Barcelona, 4-6 July 2016, 8352-8359.

Schwartz, D. (1995). The emergence of abstract dyad representations in dyad problem solving. Journal of the Learning Sciences, 4(3), 321-54.

Spronken-Smith, R., \& Walker, R. (2010). Can inquiry-based learning strengthen the links between teaching and disciplinary research? Studies in Higher Education, 35(6), 723740. 